\title{
Thoraco-abdominal enteric duplication
}

INSERM

\section{Source}

INSERM. (1999). Orphanet: an online rare disease and orphan drug data base. Thoracoabdominal enteric duplication. ORPHA:1759

Thoraco-abdominal enteric duplication is a rare, syndromic intestinal malformation characterized by single or multiple smooth-walled, often tubular, cystic lesions, which on occasion contain ectopic gastric mucosa, located in the thorax (usually in the posterior mediastinum and to the right of the midline) and in the abdomen. Infants usually present with respiratory distress and older patients with heartburn, abdominal pain, vomiting and/or melena. Vertebral anomalies in the lower cervical spine, with CNS involvement, are frequently present and complications, such as bowel obstruction, perforation and intussusception, have also been reported. 